\title{
Measuring the Capacity and Transaction Time of Cash and Electronic Toll Collection Systems
}

\author{
Rudy Hermawan Karsaman ${ }^{1, *}$, Yans Mahendra ${ }^{2}$, Harmein Rahman ${ }^{1}$ \\ \& Sony Sulaksono ${ }^{1}$ \\ ${ }^{1}$ Transportation Engineering Research Group, Institut Teknologi Bandung, \\ Jalan Ganesha 10, Bandung 40132, Indonesia \\ ${ }^{2}$ Secretariat General of Ministry of Public Works, \\ Jalan Pattimura 20, Jakarta 12110, Indonesia \\ *Email: rudy@trans.si.itb.ac.id
}

\begin{abstract}
A long queue can occur at tollgates due to the amount of transaction time required to perform ticket payment and toll fee collection. This problem can be addressed by the use of an electronic toll collection (ETC) system. A case study conducted on the Jakarta Intra Urban, Cikupa-Merak, and Cawang Pluit Toll Roads suggests that the queueing at the tollgates when modelled followed a Poisson distribution. The average cash transaction time was approximately 5 to 6 seconds, while the ETC transaction time was only 4 seconds. Furthermore, the capacity of the cash system gate was 550 to 620 vehicles/hour (which is above the minimum service standard of 450 vehicles/hour), whereas the electronic gate capacity was 770 to 870 vehicles/hour. This study demonstrates that the ETC system is more effective than the cash system in terms of reducing the number of queueing vehicles.
\end{abstract}

Keywords: electronic toll collection system; minimum service standard; tollgate capacity; toll queueing model; transaction time.

\section{$1 \quad$ Introduction}

The rapid development of toll roads in Indonesia has led to an increase in the number of vehicles and economic activities; however, the expectations of road users of faster and convenient accessibility to toll roads have not been fully accommodated. One of the problems encountered by the road users are long queues at the tollgates due to the transaction time required for ticket payment and toll fee collection. Therefore, a toll fee collection system that is fast and secure, both for the user and the operator, is required.

The toll fee collection system covers several aspects: service and control process, administration of revenues, and other supporting processes. Therefore, the toll fee collection system should be based on several considerations, including the following: a rapid and secure service in which the transaction occurs with the correct tariff, a compatible system that can be integrated with

Received March $4^{\text {th }}, 2013,1^{\text {st }}$ Revision August $21^{\text {st }} 2013,2^{\text {nd }}$ Revision February $5^{\text {th }} 2014,3^{\text {rd }}$ Revision March $24^{\text {th }}, 2014$, Accepted for publication April $11^{\text {th }}, 2014$.

Copyright ( 2014 Published by ITB Journal Publisher, ISSN: 2337-5779, DOI: 10.5614/j.eng.technol.sci.2014.46.2.5 
the existing system and its future development, the use of technology and human resources management allowing maximum service, and efficiency in each aspect for the operator company [1].

There are two types of electronic toll collection (ETC) systems, namely semiautomatic and fully automatic types. Several countries use a semi-automatic system in which each vehicle must stop to have a toll card scanned and then must wait until the gate is open. In other countries, the transaction at the gates uses a fully automatic system, whereby the vehicles do not have to stop because the transaction occurs wirelessly between an electronic on-board unit in the vehicle and a computer network at the gate.

There are several advantages to using an ETC system: increase in tollgate capacity; decrease in congestion at the tollbooth; reduction in transaction operation cost and time, which leads to fuel savings; reduction in gas emissions; elimination of human errors in transactions; and simplification of the operation for the toll users [2]. Moreover, an ETC system also offers additional intangible benefits, such as a reduction in stress and anxiety, both for the users and the operators [3], and a lowering of the cost of providing more booths or other parts of the infrastructure [4].

The first ETC system was implemented in Norway in 1987, followed by Italy, France, Spain, and Portugal [5]. In Indonesia, the implementation of ETC systems was introduced in 2007 and, so far, only a few toll road operators have applied this system. According to toll road operator Jasa Marga, the total percentage of drivers who use ETC systems in Indonesia was approximately $10 \%$ in the year 2013. This percentage is much lower than the fraction of ETC system users in Japan and Queensland, where the percentage of users was approximately $60 \%$ in 2006 [6] and 40\% in 2005 [7], respectively.

In Indonesia, based on the Ministry of Public Work decree No. 392/PRT/M/2005 [8], the Minimum Service Standard (MSS) at toll roads has been implemented effectively. The MSS parameters that should be achieved at toll roads include the physical condition of the toll road and the service provided to the user. The values of these parameters are routinely evaluated using direct field surveys in order to maintain or increase the service quality for the user. The Indonesian Highway Capacity Manual [9] defines capacity as the traffic flow to be maintained in a certain highway segment at a certain condition per a certain time period. For a tollgate, the conditions that can affect tollgate capacity are: driver behaviour, toll tariff, skill of the toll collector, and the payment or collection mechanism [10]. Hence, tollgate capacity can be defined as the maximum number of vehicles that can be serviced in a certain period. 
The Korean Highway Corporation $(\mathrm{KHC})$ calculated tollgate capacity $\mathrm{C}=$ $3600 /$ service-time, with service time taken as 8 seconds [11].

To improve the application of the fully electronic system, an evaluation of the transaction time and the tollgate capacity should be conducted. This paper presents the evaluation of a queueing model and tollgate capacity based on vehicle arrival time and required transaction time. Furthermore, a comparative study between the capacity of a cash payment system and an electronic payment system at the tollgate is described in the following.

\section{$2 \quad$ Queueing Theory}

\subsection{Queueing Process}

The basic processes and assumptions used in the queueing model are as follows (Figure 1).

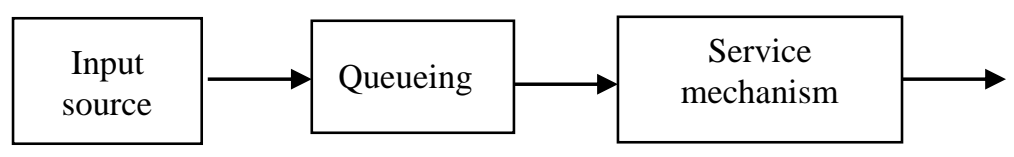

Figure 1 Basic Queueing Process [12].

The customer requesting the service will arrive at a certain time point from the source and join the queueing system. At a certain time point, one of the queue members will be served in accordance with queueing discipline. The service required is executed using a certain service mechanism that allows the customer to leave the queueing system upon completion.

\subsection{Queueing Elements}

There are three main components in queueing theory, viz. level of arrival $(\lambda)$, level of service $(\mu)$, and queueing discipline.

\section{Arrival level $(\lambda)$}

The level of arrival $(\lambda)$ is the number of people or vehicles that arrive at one or several service points at a certain time point, usually defined in people or vehicle units per hour or per minute. In some reports, a Poisson distribution model was found to be suitable for modelling the arrival pattern of vehicles under uncongested traffic flow conditions. 


$$
\mathrm{P}^{n}=\frac{(\lambda)^{n} e^{-\lambda}}{n !}
$$

where: $\mathrm{P}(\mathrm{n}) \quad=$ probability of arrival of $\mathrm{n}$ vehicles within the time range

$\lambda=$ vehicle arrival level at a certain time point

$\mathrm{e} \quad=$ natural number $(\mathrm{e}=2.718)$

\section{Service level $(\mu)$}

Level of service $(\mu)$ is the number of people or vehicles that can be served at one or several service points within a certain time, which is usually defined as people or vehicle units per hour or per minute. Service time (st) is the time required to serve a vehicle, usually stated in minutes per vehicle or per person. The value of $\rho$ is the ratio of arrival level $(\lambda)$ to service level $(\mu)$, with the condition that its value has to be less than 1 [13].

$$
\rho=1+\frac{\lambda}{\mu}<1
$$

If $\rho>1$, then the arrival level is higher than the service level, which indicates a longer queue (uninfinity).

\section{Queueing Discipline}

Queueing discipline assigns the rule to select which of the queue members to serve. There are four types of rules, namely First Come First Serve (FCFS), Last Come First Serve (LCFS), Service in Random Order (SIRO), and General Discipline (GD) [14]. The serving type most often used in the transportation or traffic field is First In First Out (FIFO) or First Come First Served (FCFS), where people or vehicles that arrive first at the service point are served first, such as in a queue formed at a tollgate [15].

\subsection{Queueing Model and Parameters}

The parameters used in the queueing analysis, namely Ls, Lq, Ws, and Wq, are defined as follows:

Ls $\quad=$ number of people or vehicles in the system per time unit.

$\mathrm{Lq}=$ number of people or vehicles in the queue per time unit.

Ws = time for people or vehicle in the system.

$\mathrm{Wq}=$ time for people or vehicle in the queue.

Some of the queueing models were developed based on assumption of arrival pattern, departure pattern and queueing discipline. The M/M/s queueing model is a model whereby the arrival and the service distribution patterns follow an exponential-negative (Poisson) distribution and $\mathrm{s}$ is the number of service lanes. This model is suitable for modelling tollgate queueing. 


$$
\begin{aligned}
& \text { Po }=\frac{1}{\left[\sum_{n=0}^{s-1} \frac{\rho^{n}}{n !}\right]+\left[\frac{\rho^{s}}{s !\left(1-\frac{\rho}{s}\right)}\right]} \\
& \mathrm{Lq}=\frac{P o \cdot \rho^{s+1}}{s ! s}+\left[\frac{1}{\left(1-\left(\frac{\rho}{s}\right)\right)^{2}}\right]
\end{aligned}
$$

where:

Po = chance of no vehicles in the system.

$\mathrm{Lq}=$ number of vehicles in the queue (vehicles per time unit).

$\mathrm{s} \quad=$ number of service lanes.

\section{$3 \quad$ Methodology}

\subsection{Tollgate Location}

The research was conducted at the Jakarta Intra Urban Toll Road, the CikupaMerak Toll Road, and the Cawang-Pluit Toll Road.

\subsection{Preparation and Data Collection}

The data collected consisted of primary and secondary survey data. The primary data were obtained from direct field surveys, whereas the secondary data, namely the gate layout and the E-Toll information and its usage, were obtained from the toll operators. The survey was performed on Monday, Wednesday, and Saturday to represent both working day and weekend day conditions.

\subsection{Vehicle Arrival Times}

Observation of arrival times was performed by counting the number of vehicles that entered the tollgate at a certain time point. One tollgate was selected for each of the toll road links operated by a different operator. The first step was to determine the point of the longest queueing boundary, where the speed of the vehicles was still constant when they entered the tollgate. The next step was to count the number of vehicles every 5 minutes.

\subsection{Average Transaction Times}

The transaction time of each vehicle entering the booth was recorded using a stopwatch. A total number of 80 vehicles for each booth were subjected to this study. The transaction time started from the time the driver provided the toll payment, followed by the time the toll staff attendant received the money or card, and ended at the time the driver reached out to receive the change and/or receipt. 


\subsection{Data Analysis}

The obtained data were analysed to determine the length of the queue and the capacity of the gate based on a fixed arrival level $(\lambda)$ at various service times $(\mu)$ for the payment systems of all booths using mixed systems (cash and electronic systems) and all booths using ETC systems. The work program and the analysis diagram are shown in Figure 2.

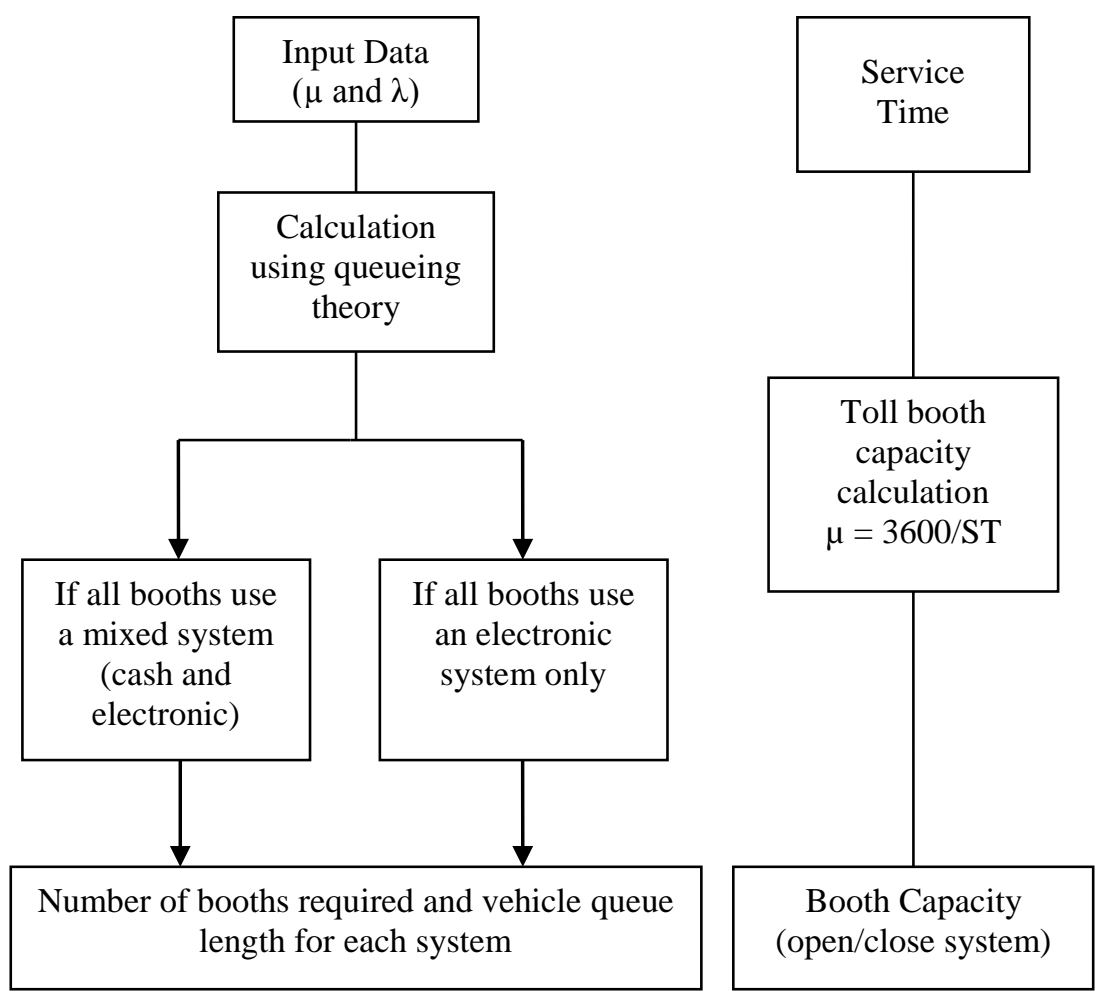

Figure 2 Work and Analysis Diagram.

\section{$4 \quad$ Results and Model Estimation}

\subsection{Cililitan Tollgate}

Cililitan Tollgate (TG) has 14 booths, with two special booths for ETC, namely booths number 6 and 7 (Figure 3). The location where vehicle arrival was recorded was $350 \mathrm{~m}$ before the gate. Figure 4 demonstrates an example of the field observation data of the traffic flow or the vehicle arrival fluctuation at Cililitan TG. 


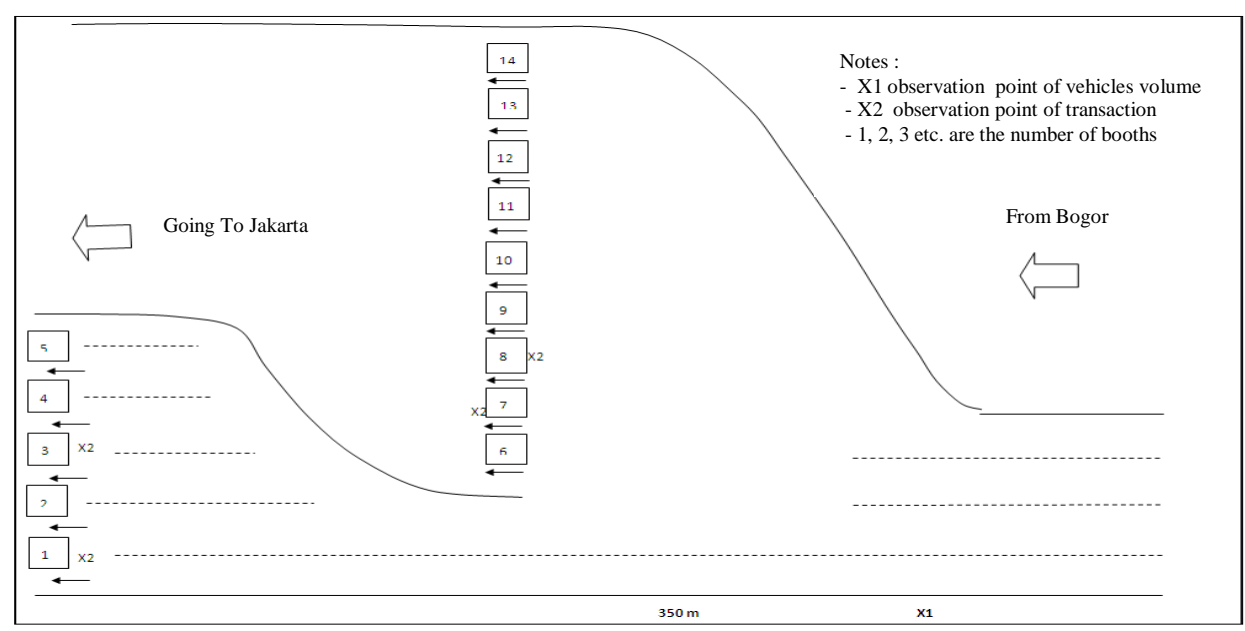

Figure 3 Cililitan TG Scenario.

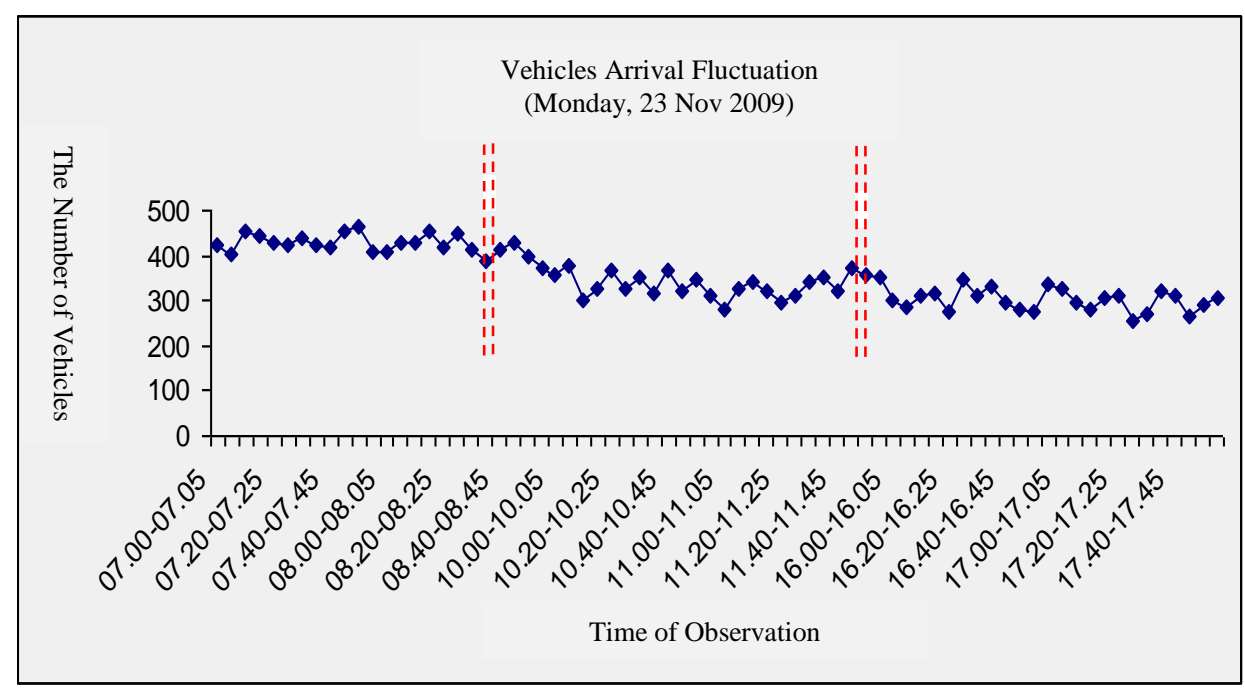

Figure 4 Arrival Fluctuation of Vehicles at the Cililitan TG.

\subsection{Cikupa Tollgate}

Cikupa Tollgate has 10 booths, of which seven booths were used for the direction to Jakarta with a distribution of two booths from Cikupa and five booths from Merak, while the other three booths were functioning for the direction to Merak. Cikupa TG did not provide special lanes for ETC; therefore, electronic payment was mixed with cash payment. The location of observation was $1 \mathrm{~km}$ before the gate to the Jakarta direction. 


\subsection{Tanjung Priok Tollgate}

When this survey was conducted, all five booths available at Tanjung Priok Tollgate used cash and ETC systems. Note that currently, a single ETC system is implemented at Tanjung Priok TG.

\subsection{Service Time Survey}

Samplings for the service time survey at Cililitan, Cikupa, and Tanjung Priok were consecutively taken at several booths, i.e. booth numbers 1, 3, 6 (ETC), 7 (ETC), and 8; booth numbers 5, 6, and 7; and booths numbers 1, 2, and 3, respectively. Examples of the data for the cash and mixed systems are presented in Table 1 and Table 2, respectively.

Table 1 Transaction Time Data Booth 1 Cililitan using Cash System.

\begin{tabular}{|c|c|c|c|c|c|c|c|}
\hline Veh & $\begin{array}{c}\text { TT } \\
\text { (seconds) }\end{array}$ & Veh & $\begin{array}{c}\text { TT } \\
\text { (seconds) }\end{array}$ & Veh & $\begin{array}{c}\text { TT } \\
\text { (seconds) }\end{array}$ & Veh & $\begin{array}{c}\text { TT } \\
\text { (seconds) }\end{array}$ \\
\hline 1 & 5.09 & 21 & 3.22 & 41 & 4.29 & 61 & 3.42 \\
\hline 2 & 3.45 & 22 & 5.56 & 42 & 5.51 & 62 & 5.24 \\
\hline 3 & 7.1 & 23 & 7.09 & 43 & 5.7 & 63 & 3.37 \\
\hline 4 & 10.55 & 24 & 4.01 & 44 & 4.44 & 64 & 4.88 \\
\hline 5 & 7.59 & 25 & 8.29 & 45 & 9.66 & 65 & 6.03 \\
\hline 6 & 4.01 & 26 & 5.07 & 46 & 4.03 & 66 & 3.81 \\
\hline 7 & 5.13 & 27 & 3.53 & 47 & 7.22 & 67 & 5.59 \\
\hline 8 & 3.67 & 28 & 3.66 & 48 & 4.71 & 68 & 3.3 \\
\hline 9 & 11.21 & 29 & 7.33 & 49 & 6.49 & 69 & 12.59 \\
\hline 10 & 3.35 & 30 & 9.42 & 50 & 3.94 & 70 & 4.76 \\
\hline 11 & 3.07 & 31 & 3.77 & 51 & 5.57 & 71 & 7.13 \\
\hline 12 & 9.11 & 32 & 11.5 & 52 & 4.13 & 72 & 3.18 \\
\hline 13 & 5.29 & 33 & 5.78 & 53 & 8.35 & 73 & 7.56 \\
\hline 14 & 7.34 & 34 & 3.12 & 54 & 4.68 & 74 & 5.88 \\
\hline 15 & 9.72 & 35 & 6.16 & 55 & 4.22 & 75 & 3.76 \\
\hline 16 & 4.57 & 36 & 7.58 & 56 & 7.59 & 76 & 7.43 \\
\hline 17 & 8.19 & 37 & 4.29 & 57 & 7.41 & 77 & 7.81 \\
\hline 18 & 3.12 & 38 & 3.87 & 58 & 4.85 & 78 & 3.65 \\
\hline 19 & 11.56 & 39 & 6.75 & 59 & 6.33 & 79 & 5.93 \\
\hline 20 & 5.75 & 40 & 4.41 & 60 & 4.77 & 80 & 3.84 \\
\hline
\end{tabular}


Table 2 Transaction Time Data in Booth 1 Tg Priok using Mixed System.

\begin{tabular}{|c|c|c|c|c|c|c|c|}
\hline Veh & $\begin{array}{c}\text { TT } \\
\text { (seconds) }\end{array}$ & Veh & $\begin{array}{c}\text { TT } \\
\text { (seconds) }\end{array}$ & Veh & $\begin{array}{c}\text { TT } \\
\text { (seconds) }\end{array}$ & Veh & $\begin{array}{c}\text { TT } \\
\text { (seconds) }\end{array}$ \\
\hline 1 & 5.72 & 21 & 4.29 & 41 & 6.34 & 61 & 5.87 \\
\hline 2 & 9.56 & 22 & 12.12 & 42 & 3.41 & 62 & 7.24 \\
\hline 3 & 4.12 & 23 & 5.45 & 43 & 7.22 & 63 & 4.55 \\
\hline 4 & 3.97 & 24 & 5.32 & 44 & 9.44 & 64 & 4.42 \\
\hline 5 & 5.69 & 25 & 4.43 & 45 & 7.31 & 65 & 9.31 \\
\hline 6 & 8.53 & 26 & 3.81 & 46 & 3.59 & 66 & 5.65 \\
\hline 7 & 9.38 & 27 & 9.55 & 47 & 4.52 & 67 & 3.46 \\
\hline 8 & 7.49 & 28 & 4.28 & 48 & 5.18 & 68 & 4.61 \\
\hline 9 & 15.66 & 29 & 5.68 & 49 & 3.92 & 69 & 9.14 \\
\hline 10 & 11.31 & 30 & 7.23 & 50 & 5.62 & 70 & 6.08 \\
\hline 11 & 6.04 & 31 & 5.84 & 51 & 7.46 & 71 & 7.16 \\
\hline 12 & 3.32 & 32 & 9.81 & 52 & 9.15 & 72 & 4.37 \\
\hline 13 & 7.51 & 33 & 4.75 & 53 & 3.65 & 73 & 5.58 \\
\hline 14 & 5.07 & 34 & 4.69 & 54 & 6.22 & 74 & 9.28 \\
\hline 15 & 11.65 & 35 & 7.56 & 55 & 3.23 & 75 & 3.23 \\
\hline 16 & 7.45 & 36 & 6.20 & 56 & 9.27 & 76 & 4.49 \\
\hline 17 & 3.81 & 37 & 3.39 & 57 & 4.52 & 77 & 7.37 \\
\hline 18 & 4.54 & 38 & 7.67 & 58 & 5.57 & 78 & 5.13 \\
\hline 19 & 3.25 & 39 & 4.76 & 59 & 12.01 & 79 & 8.03 \\
\hline 20 & 4.48 & 40 & 3.43 & 60 & 4.23 & 80 & 5.17 \\
\hline & \multicolumn{7}{|l|}{ Using ETC } \\
\hline
\end{tabular}

\subsection{Service Time Adequacy Data Test}

The required numbers of samples were calculated based on the degree of accuracy and the level of confidence. For each gate, the number of booths was three with 80 vehicles for each booth. The test was performed using the following formula.

$$
N^{\prime}=\left[\frac{40 \sqrt{\mathrm{N} \Sigma \mathrm{xj}^{2}-(\Sigma \mathrm{xj})^{2}}}{\Sigma \mathrm{xj}}\right]^{2}
$$

where:

$\mathrm{N}^{\prime} \quad=$ Number of measurements required 
$\mathrm{N} \quad=$ Number of observations

An example of a calculation for booth 1 at Cililitan TG is as follows:

$$
\begin{aligned}
N^{\prime} & =\left[\frac{40 \sqrt{80\left(5.09^{2}+3.45^{2}+\cdots+3.84^{2}\right)-(5.09+3.45+\cdots+3.84)^{2}}}{(5.09+3.45+\cdots+3.84)}\right]^{2} \\
& =25.96<\mathrm{N}, \text { then the data are adequate. }
\end{aligned}
$$

\subsection{Vehicle Arrival Time Distribution}

The distribution pattern of the vehicle arrival time obtained from the field survey as described previously was further analysed and tested using a ChiSquared Goodness of Fit Test. It was found that the vehicle arrival time followed a Poisson distribution pattern.

\subsection{Tollgate Transaction Time Distribution}

The data for each booth were tested by a comparative t-test to determine whether the transaction time data at the gate were homogeneous or not. The test was performed using SPSS for Windows. For example, at Cililitan TG, because the samples were obtained for booth numbers 1,3 , and 8 , the tests were performed for booth numbers 1 and 3,1 and 8, and then 3 and 8. From the calculation, it was found that the transaction data for booths 1 and 3 were homogenous.

Furthermore, to determine the transaction time distribution pattern of the samples, a Chi-Squared Goodness of Fit Test was performed. From analysis, it could be determined that the transaction time data followed an exponential distribution.

\subsection{Tollgate Requirement Analysis}

The length of the queue and the required service time, as well as the number of additional gates required to shorten queueing, can be analysed based on the number of vehicle arrivals, the transaction time, and the number of existing gates.

\subsubsection{Cash Tollgate}

For the example of Cililitan TG, with the arrival level $(\lambda)$ of 5259 vehicles/h and the average transaction time of $5.8 \mathrm{sec} / \mathrm{vehicle}$ for the cash system and 4.7 sec/vehicle for the ETC system, the gate capacities were: 


$$
\mu_{m}=\frac{3600}{5.85}=618.55 \text { veh } / \text { hour } \mu_{e}=\frac{3600}{4.68}=769.23 \text { veh } / \mathrm{h}
$$

Lq (average queue length) was based on the peak hour calculation/observation.

At Cililitan TG, there are 14 booths, therefore:

- For the cash system:

$$
\rho=\frac{\lambda}{\mu}=\frac{5259}{618.55}=8.5
$$

The number of vehicles in the queue (Lq):

$$
\begin{aligned}
& \text { Po }=\frac{1}{\left[\sum_{n=0}^{s-1} \frac{\rho^{n}}{n !}\right]+\left[\frac{\rho^{s}}{s !\left(1-\frac{\rho}{s}\right)}\right]}=0.0213 \\
& \mathrm{Lq}=\frac{\text { Po. } \rho^{s+1}}{s ! s}+\left[\frac{1}{\left(1-\left(\frac{\rho}{s}\right)\right)^{2}}\right]=17 \text { veh } \\
& W q=\frac{\rho+L q}{\lambda}-\frac{1}{\mu}=\frac{8.5+17}{5259}-\frac{1}{618.55}=67.9 \text { seconds } \\
& W s=\frac{\rho+L q}{\lambda}=\frac{8.5+12}{5259}=73.7 \text { seconds }
\end{aligned}
$$

- If using the ETC:

$$
\begin{aligned}
& \rho=\frac{\lambda}{\mu}=\frac{5259}{769.23}=6.84 \\
& \text { Po }=\frac{1}{\left[\sum_{n=0}^{s-1} \frac{\rho^{n}}{n !}\right]+\left[\frac{\rho^{s}}{s !\left(1-\frac{\rho}{s}\right)}\right]}=0.0413 \\
& \mathrm{Lq}=\frac{P o \cdot \rho^{s+1}}{s ! s}+\left[\frac{1}{\left(1-\left(\frac{\rho}{s}\right)\right)^{2}}\right]=10 \text { veh } \\
& W q=\frac{\rho+L q}{\lambda}-\frac{1}{\mu}=\frac{6.84+10}{5259}-\frac{1}{769.23}=49.2 \text { seconds }
\end{aligned}
$$




$$
W s=\frac{\rho+L q}{\lambda}=\frac{6.84+10}{5259}=53.9 \text { seconds }
$$

- If one new booth is added:

$$
\begin{aligned}
& \rho=\frac{\lambda}{\mu}=\frac{5259}{618.55}=8.5 \\
& \text { Po }=\frac{1}{\left[\sum_{n=0}^{s-1} \frac{\rho^{n}}{n !}\right]+\left[\frac{\rho^{s}}{s !\left(1-\frac{\rho}{s}\right)}\right]}=0.0457 \\
& \mathrm{Lq}=\frac{P o \cdot \rho^{s+1}}{s ! s}+\left[\frac{1}{\left(1-\left(\frac{\rho}{s}\right)\right)^{2}}\right]=12 \text { veh } \\
& W q=\frac{\rho+L q}{\lambda}-\frac{1}{\mu}=\frac{8.5+11}{5259}-\frac{1}{618.55}=56.2 \text { seconds } \\
& W s=\frac{\rho+L q}{\lambda}=\frac{8.5+12}{5259}=62 \text { seconds }
\end{aligned}
$$

\subsubsection{Cash and Electronic Tollgate Combination}

The implementation of ETC was performed sequentially in the observed tollgates; therefore, an analysis of the number of booths required was necessary. The estimation of the number of booths required can be performed using the following calculation.

$$
\text { Terms : } \rho<1 ; \frac{\lambda_{m} / s}{\mu_{m}}+\frac{\lambda_{e} / s}{\mu_{e}}<1
$$

For the example of the Priok TG:

$$
\begin{aligned}
& \text { Level of Service }: \frac{3600}{6.54}=550.54 \text { veh } / \text { hour } \\
& \text { and } \mu_{e}=\frac{3600}{4.13}=871.67 \text { veh } / \text { hour }
\end{aligned}
$$

Level of Arrival : $\lambda=1362$ veh/hour 
Furthermore, the numbers of cash gates and ETC gates required were determined based on the number of arrivals and the transaction times from both the cash and ETC systems, which were calculated separately.

$$
\frac{\lambda_{e} / s}{\mu_{e}}+\frac{\lambda_{m} / s}{\mu_{m}}<1 \text { or } \frac{408.6 / 1}{871.67}+\frac{953.4 / 4}{550.46}=0.90<1
$$

Therefore, for Tanjung Priok TG, the optimal combination was 1 ETC gate and 4 cash gates.

\subsection{Queueing Parameter Analysis Results}

The results of the queueing parameter calculation were based on the arrival level and the transaction time (Tables 3, 4, and 5). It was observed that the decrease in the average number of vehicles in the queue was insignificant, which may be due to the relatively small decrease in the transaction time.

Table 3 Queueing Parameter Analysis Results for Cash systems.

\begin{tabular}{cccc}
\hline Queueing Parameter & Cililitan & Cikupa & TanjungPriok \\
\hline Lq (veh) & 17 & 9 & 5 \\
Ls (veh) & 18 & 10 & 6 \\
Wq (seconds) & 67.9 & 27.8 & 19.7 \\
Ws (seconds) & 73.7 & 23.2 & 26.2 \\
\hline
\end{tabular}

Table 4 Queueing Parameter Analysis Results for ETC systems.

\begin{tabular}{cccc}
\hline Queueing Parameter & Cililitan & Cikupa & Tanjung Priok \\
\hline Lq (veh) & 10 & 3 & 1 \\
Ls (veh) & 11 & 4 & 2 \\
Wq (seconds) & 49.2 & 11.3 & 6.7 \\
Ws (seconds) & 53.9 & 15.5 & 11.7 \\
\hline
\end{tabular}

Table 5 Gate Capacity Analysis Results.

\begin{tabular}{ccccc}
\hline $\begin{array}{c}\text { Payment } \\
\text { System }\end{array}$ & $\begin{array}{c}\text { Actual Capacity } \\
\text { Cililtan } \\
\text { (vehicles/hour) }\end{array}$ & $\begin{array}{c}\text { Actual Capacity } \\
\text { Cikupa } \\
\text { (vehicles/hour) }\end{array}$ & $\begin{array}{c}\text { Actual Capacity } \\
\text { T. Priok } \\
\text { (vehicles/hour) }\end{array}$ & $\begin{array}{c}\text { Theoretical } \\
\text { Capacity } \\
\text { (vehicles/hour) }\end{array}$ \\
\hline ETC system & 769 & 859 & 871 & $1200^{*}$ \\
Cash system & 618 & 558 & 551 & 450 (MSS) \\
\hline
\end{tabular}

Note: $*$ Transaction time is assumed to be 3 seconds; hence the capacity $=3600 / 3$ seconds

Based on the results presented in Table 5, the capacity of the cash system was significantly higher than the Minimum Service Standard (MSS), and as 
expected, the capacity of the ETC system was much higher. Therefore, it is inevitable that the cash systems should be converted to ETC systems. Because the conversion cannot be implemented directly at all tollgates, the number of ETC systems should be increased gradually, considering a cost and benefit analysis [16]. However, because a cash system is required, all of the cash systems cannot be removed.

\section{Conclusions}

Based on actual observations and measurements in the field, it was found that the average transaction time using a cash system at the investigated tollgates was 5 to 6 seconds, while the use of an ETC decreased the transaction time to 4 seconds. Furthermore, the cash tollgate capacity was approximately 550 to 620 vehicles/hour, whereas due to the more rapid transaction time, the ETC tollgate capacity reached 770 to 870 vehicles/hour. The findings of this study can be used in the design stage of a tollgate to estimate the number of ETC gates required or to improve the MSS to include the ETC's level of service (i.e. the maximum transaction time and the minimum gate capacity that should be achieved).

\section{References}

[1] Karsaman, R.H., Evaluation of ETC system applications in Indonesia, National Conference on Information and Communication e-Indonesian Initiative Forum V, June 2009, Bandung.

[2] Chaudary, R.H., A Model for the Benefits of Electronic Toll Collection System, Magister Thesis, University of South Florida, Florida, 2003.

[3] Riley, P.F., The Tolls of Privacy: An Underestimated Roadblock for Electronic Toll Collection Usage, Computer Law \& Security Report, 24, pp. 521-528, 2008.

[4] Kamarulazizi, K. \& Ismail, W., Electronic Toll Collection System Using Passive RFID Technology, Journal of Theoretical and Applied Information Technology, 22(2), pp. 70-76, 2010.

[5] Ito, T., Process Simulation Approach to Design and Evaluation of Toll Plaza with ETC, I. J. of Simulation, 6(5), pp. 14-21, 2004.

[6] Shitama, T., Horiguchi, R., Akahane, H. \& Xing, J., Traffic Simulation for Expressway Toll Plaza Based on Successive Vehicle Tracking Data, Proceeding of International Symposium of Transport Simulation, pp. 121, Lausanne, Switzerland, September 2006.

[7] Poon, N. \& Dia, H., Evaluation of Toll Collection Performance Using Traffic Simulation, $27^{\text {th }}$ Conference of Australian Institutes of Transport Research (CAITR 2005), AITR, Brisbane, 7-9 December 2005. 
[8] Minister of Public Works Decree No. 392/PRT/M/2005 about Toll Road Minimum Service Standard, Jakarta.

[9] Ministry of Public Works, Indonesia Highway Capacity Manual (IHCM), Jakarta, 1997.

[10] Sasongko, A.S.P., Tandem Toll Booth to Alleviate Collection Delay, Magister Thesis, Bandung, Institut Teknologi Bandung, 1987.

[11] Chang, J., Oh, C. \& Chang, M., Effects of traffic condition (v/c) on safety at freeway facility sections, Transportation Research Circular E-C018: $4^{\text {th }}$ International Symposium on Highway Capacity, 1998.

[12] Hillier, F.S. \& G.J., Lieberman, Introductions to Operations Research, $8^{\text {th }}$ Ed., Singapore, McGraw Hill Book Co, 1995.

[13] Tamin, O.Z., Planning, Modelling, and Transportation Engineering: Theory, Example and Application (Text in Indonesian), Bandung, Penerbit ITB, 2008.

[14] Taha, H.A., Operation Research an Introduction. $8^{\text {th }}$ Edition, New Jersey, Pearson Prentice Hall, 1997.

[15] Morlok, E.K., Introduction of Transportation Planning and Engineering, New York, McGraw-Hill Book Co, 1978.

[16] Levinson, D. \& Chang, E., A Model for Optimizing Electronic Toll Collection Systems, Transportation Research Part A: Policy and Practice, 37(4), pp. 293-314, 2003. 